\title{
Regional Immunoreactivity of Pax6 in the Neurogenic Zone After Chronic Prenatal Hypoxia
}

\author{
KEUMYOUNG SO ${ }^{1}$, YOONYOUNG CHUNG ${ }^{2}$, SUN-KYOUNG YU ${ }^{3}$ and YONGHYUN JUN ${ }^{2}$ \\ ${ }^{1}$ Department of Anesthesiology and Pain Medicine, Chosun University Hospital, Gwang-ju, Republic of Korea; \\ ${ }^{2}$ Department of Anatomy, School of Medicine, Chosun University, Gwang-ju, Republic of Korea; \\ ${ }^{3}$ Department of Oral anatomy, School of Dentistry, Chosun University, Gwang-ju, Republic of Korea
}

\begin{abstract}
Background/Aim: Neurogenesis is a complex process to generate new neurons from neural progenitor cells. Neural progenitor cells are observed in two principal neurogenic regions of the forebrain, the subventricular zone and the subgranular zone of the hippocampal dentate gyrus. The cerebral cortex also plays a role as the neurogenic zone under hypoxic conditions. Hypoxia has many effects on neurogenesis, but the effect of chronic prenatal hypoxia on paired box 6 (Pax6), a protein that plays an important role in neurogenesis, has not been studied in vivo. In the present study, we used a rat model to evaluate the effect of hypoxia on Pax6 immunoreactivity. Materials and Methods: Hypoxia status was induced by unilateral uterine-artery ligation in pregnant rats. The fetuses were obtained from the uterine horn on the twenty-first day of pregnancy and immunohistochemistry of the fetal brain was examined regarding anti-hypoxia-induced factor $1 \alpha$ and Pax6 antibody. Results: The density of HIFla-IR cells in the hypoxia group was greater than the density of HIFI $\alpha-I R$ cells in the control group in the subventricular zone, subgranular zone, and cerebral cortex. The density of Pax6-IR cells in the hypoxic group was higher in both the subventricular zone and the subgranular zone than in the control group. However, the density of Pax6-IR cells in the cerebral cortex was lower in fetuses that experienced hypoxia than in control fetuses. Conclusion: These results suggest that Pax6 immunoreactivity showed diverse patterns
\end{abstract}

This article is freely accessible online.

Correspondence to: Yonghyun Jun, Department of anatomy, School of medicine, Chosun University, 375 Seosuk-dong, Dong-Gu, Gwangju 501-759, Republic of Korea. Tel: +82 10 28862973, Fax: +82062 2341474, e-mail: jyh1483@chosun.ac.kr

Key Words: Hypoxia, prenatal, neurogenesis, Pax6, immunoreactivity, neural progenitor cell. in the neurogenic zone after prenatal hypoxia and Pax6 has important effects on neurogenesis.

Neurogenesis is a complex process by which new neurons are generated from neural progenitor cells. Neural progenitor cells exist in two principal neurogenic regions of the forebrain, the subventricular zone (SVZ) and the subgranular zone (SGZ) of the hippocampal dentate gyrus $(1,2)$. Multipotent neural progenitor cells in those regions can give rise to neurons, astrocytes, and oligodendrocytes (3). Progenitor cells in the SGZ of the dentate gyrus proliferate and migrate to the dentate gyrus to differentiate into neuron cells (4). Neural stem cells located in the SVZ move to the olfactory bulb and cortex via the rostral migratory stream (RMS) (5).

The protein paired box 6 (Pax6) plays an important role in neurogenesis, affecting cell proliferation, differentiation, and survival during the development of the central nervous system $(6,7)$. Pax6 is expressed in early progenitor cells and has a spatiotemporal pattern that is involved in brain patterning $(8,9)$. Pax 6 is in the paired box family of proteins and is cloned on the basis of its homology to the Drosophila gene (10). Pax6 is a conserved transcription factor containing two DNA-binding domains, a paired domain and a pairedtype homeodomain (11). Pax6 was found in the nucleus of the ventricular zone cells, which are most likely radial glial cells (12). Pax6 was also observed in the embryonic neuroepithelium in the adult brain, including the SGZ and the SVZ (13).

Hypoxia has many effects on neurogenesis. Intriguingly, it appears to promote rather than repress neurogenesis. For example, after transient hypoxic injury, neurogenesis was promoted in prenatal rat brain (14). After neonatal ischemic injury, neurogenesis was triggered in the SVZ (15). However, acute hypoxic injury caused cell death and apoptosis (16). In the SVZ, neural stem cells and oligodendrocyte progenitors are susceptible to hypoxia (17). Some studies have suggested that neuronal loss by 
hypoxic insults was improved by the neurotrophic factor or erythropoietin $(18,19)$.

Some studies have reported a correlation between Pax6 expression and hypoxic conditions (20). However, the effect of chronic prenatal hypoxia on Pax6 in vivo has not been studied. The present study exposed a rat model to hypoxia to evaluate the effect of hypoxia on Pax6 immunoreactivity (IR).

\section{Materials and Methods}

Animals and surgery to induce hypoxia. Sprague-Dawley (SD) rats were supplied from a certified breeder (Damul Laboratory Animals, Daejeon, Republic of Korea) and were fed ad libitum. Rats were mated and confirmed pregnant by checking the vaginal plug. Hypoxic status was created by unilateral uterine-artery ligation in pregnant SD rats, as described in a previous study (21). Briefly, the animals were anesthetized with Zoletil (10 mg/kg; Virbac, Nice, France) and xylazine $(0.15 \mathrm{mg} / \mathrm{kg}$; Bayer, Leverkusen, Germany) on the sixteenth day of pregnancy. Each rat's lower abdomen was shaved and a midline incision was performed below the umbilicus, applying aseptic technique. Uterine arteries were located in the fat pad of the uterine horns. The ligation was performed with silk sutures $(4 / 0)$ on one of the uterine arteries at the cervical end of the site. After ligation, the abdomen was sutured with nylon and disinfected using povidoneiodine solution. This protocol was demonstrated in a previous study to significantly decrease uterine blood flow and fetal body weight, inducing growth retardation in the fetal rat (22). All animal experiments were performed according to the guidelines of Chosun University Institutional Animal Care and Use Committee.

Tissue preparation. The animals were sacrificed on the twenty-first day of pregnancy. The fetuses were obtained from the uterine horn and post-fixed with $4 \%$ paraformaldehyde (PFA) solution. Fetuses removed from the artery ligation horn were categorized as the hypoxia group $(n=10)$ and fetuses removed from opposite horn were categorized as control group $(n=10)$. The fetal brains were separated from the bodies and kept in fresh $4 \%$ PFA at $4^{\circ} \mathrm{C}$ overnight. The cerebrums were washed with distilled water. Dehydration was performed with a series of ethanol solutions. The brains were embedded in paraffin. Sagittal sections of cerebrum were cut serially and three sections which were separated by $300 \mu \mathrm{m}$ were selected from each animal. These sections were put on gelatincoated slides (Fisher Scientific, USA).

Immunohistochemistry. Deparaffinized sections were washed with $0.1 \mathrm{M}$ phosphate-buffer saline (PBS; $\mathrm{pH} 7.4$ ). Slides were cooked in a microwave oven for $10 \mathrm{~min}$ and flooded in $0.01 \mathrm{M}$ sodium citrate buffer ( $\mathrm{pH}$ 6.0). The slides underwent a process blocking endogenous peroxidase activity with $0.3 \%$ hydrogen peroxide. After the sections were rinsed with PBS, the slides were incubated with primary antibodies overnight at $4^{\circ} \mathrm{C}$ : rabbit anti-hypoxia-induced factor $1 \alpha$ (HIF $1 \alpha ; 1: 500$, Abcam, Cambridge, UK) and rabbit polyclonal Pax6 (1:500, Abcam, Cambridge, UK). On the following day, appropriate secondary antibodies were used and the avidinbiotin-peroxidase $(\mathrm{ABC})$ detection system (Vectastain $\mathrm{ABC}$ Elite Kit, Vector Laboratories, Burlingame, CA, USA) was used to visualize immunoreactivity. Counterstain was achieved with thionin and the slides were mounted with PolyMount mounting medium (Polysciences, Warrington, PA, USA).
Quantification of IR cells. The sections were analyzed with the aid of a light microscope (BX41, Olympus) connected to a digital CCD camera. Each section was subdivided randomly into five areas in the cerebral cortex, SVZ and SGZ. The density of HIF1 $\alpha$ - and Pax6- IR cells within a defined square region in each area were measured manually by two investigators who were blinded to the animal status.

Statistical analysis. We analyzed all data using the Statistical Package for Social Sciences (Information Analysis Systems, SPSS, USA). All measurements were compared between the hypoxia group and the control using Student's $t$-test. The level of statistical significance was set at $p<0.05$.

\section{Results}

HIF $1 \alpha$ immunoreactivity. The density of HIF $1 \alpha$-IR cells in the cerebral cortex was significantly greater in the hypoxia group than in the control group (Figures 1 and 2). Similarly, the densities of HIF1 $\alpha$-IR cells in the SVZ and in the SGZ of the dentate gyrus, where the neurogenic zone is located, differed between the hypoxia and control groups (Figures 1 and 2).

Pax6 immunoreactivity. Interestingly, in the cerebral cortex, the density of Pax6-IR cells was significantly lower in fetuses that experienced hypoxia than in the control group (Figures 3 and 4). However, the density of Pax6-IR cells was greater in the SVZ in the hypoxia group than in the control group. The results for the SGZ and the SVZ were similar (Figures 3 and 4).

\section{Discussion}

The immunoreactivity of Pax6 was observed in three regions, the $\mathrm{SVZ}$ and the $\mathrm{SGZ}$ of the dentate gyrus and the cerebral cortex. Both the SVZ and the SGZ are neurogenic zones, as is the cerebral cortex, particularly under hypoxic conditions (23).

The density of HIF1 $\alpha$-IR cells was higher in all three zones, the SVZ, the SGZ, and the cerebral cortex, than the density of HIF1 $\alpha$-IR cells in the control. HIF1 $\alpha$ consists of a nuclear protein complex and can bind with hypoxiaresponsive enhancers (24). HIF1 $\alpha$ exhibited striking expression during conditions of hypoxia-ischemia (25). However, HIF1 $\alpha$ expression rapidly declined with return to normoxia (26). These findings suggested that the increasing density of HIF1 $\alpha$-IR cells was related to the hypoxic state of the experimental group.

In the SVZ, the density of Pax6-IR cells was greater in the hypoxic group than in the control group. One study observed that neurological loss after hypoxic injury was improved by the activation of the $\mathrm{Wnt} / \beta$-catenin signaling pathway, which was mediated by Pax6 (27). Pax6 expression was observed in proliferating SVZ progenitors (28). Another study showed 


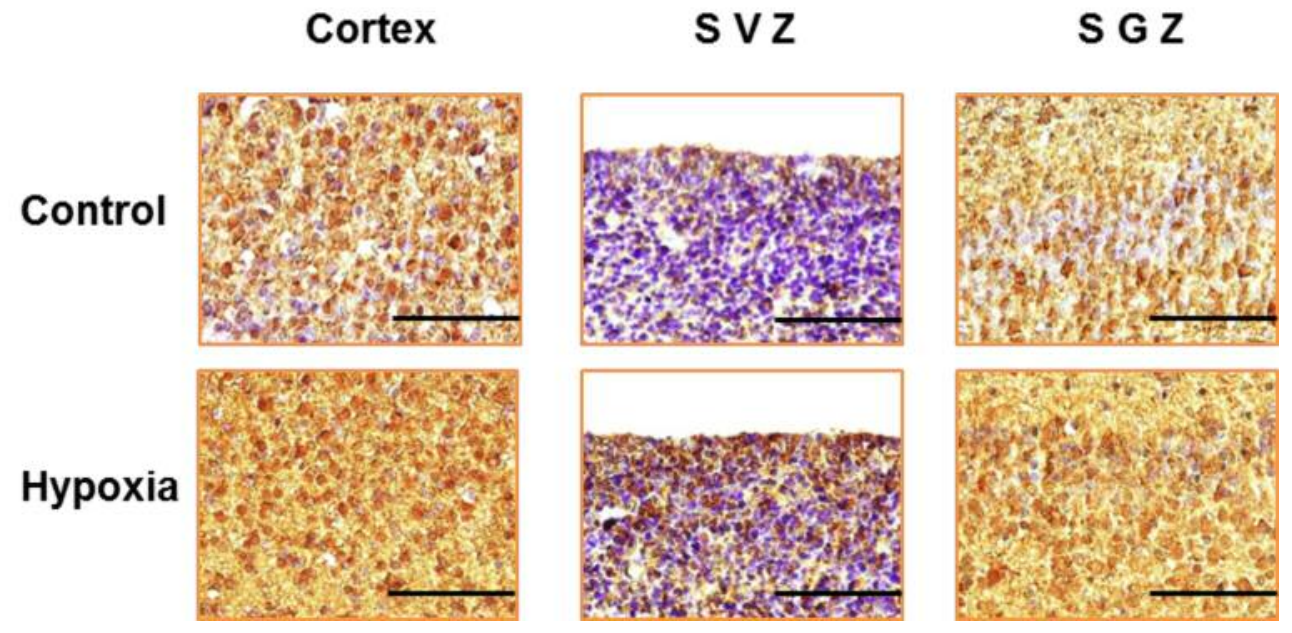

Figure 1. HIF1 $\alpha$ immunoreactivity (brown color) in the cerebral parietal cortex, SVZ, and SGZ. HIF1 $\alpha$-IR cells in the hypoxia group were more in density than in the control group. Scale bars $=100 \mu \mathrm{m}$.
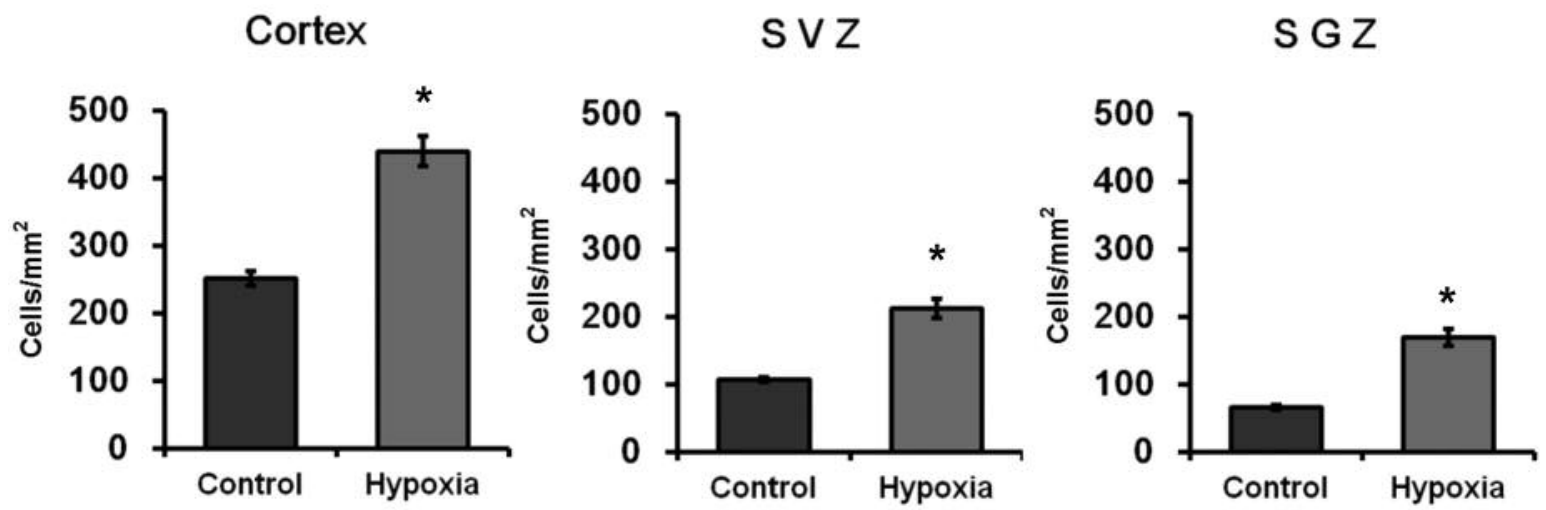

Figure 2. Densities of HIF1 $\alpha-I R$ cells in the cerebral cortex, SVZ, and SGZ in control and hypoxia fetuses. Density of HIF 1 $\alpha$-IR cells was higher in hypoxia fetuses than in the controls in all three zones, the cerebral cortex, the SVZ, and the SGZ. *p<0.005.

that hypoxic insult increased proliferation in SVZ-derived neural progenitor cell cultures and also increased Pax6 expression in SVZ tissue (29). These findings suggest that the increasing density of HIF1 $\alpha$-IR cells was correlated with the induction of neurogenesis after hypoxia.

In the SGZ, the density of Pax6-IR cells was also greater in the hypoxic group than in the control group. Some previous studies have determined that Pax6 plays a role in hippocampal neurogenesis. Pax6 is required to regulate the balance progenitor cell maintenance and neuronal progression in adult hippocampal neurogenesis (30). Overexpression of Pax6 led neuronal precursor cells to early maturation (31). However, there is insufficient evidence to explain the relationship between Pax6 and hypoxia in the SGZ.
In the cerebral cortex, the density of Pax6-IR cells was lower in the hypoxic group than in the control group. Low Pax6 expression was associated with disruption of cell migration, neuronal fate, and granule cell differentiation (32, 33). A previous study showed that chronic prenatal hypoxia caused cortical neuronal loss (34). Regarding migration of neural stem cells from the SVZ to the cerebral cortex, the alteration of Pax6 expression is related to survival of neuronal cells in the cerebral cortex.

\section{Conclusion}

Together, these results suggest that Pax6 immunoreactivity demonstrates diverse patterns in the neurogenic zone after 
Cortex

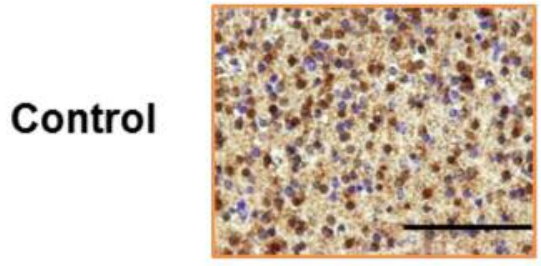

Hypoxia

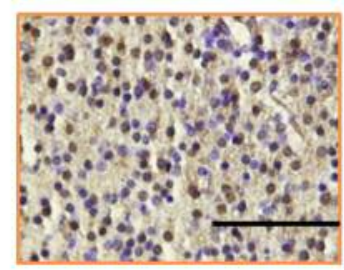

S V Z
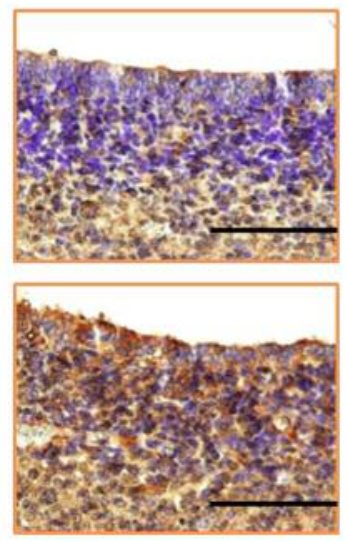

S G Z
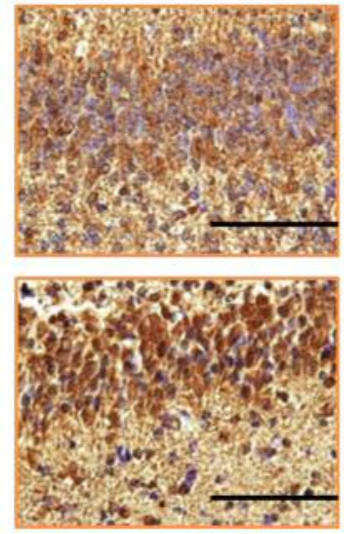

Figure 3. Pax6 immunoreactivity (brown color) in the cerebral parietal cortex, SVZ, and SGZ. The cerebral cortex contained many Pax6-IR cells in the control group but not the hypoxia group. In the SVZ and SGZ, the Pax6-IR cells were fewer in the hypoxia group than in the control group. Scale bars $=100 \mu \mathrm{m}$.


Figure 4. Densities of Pax6-IR cells in the cerebral cortex, SVZ and SGZ. The density of Pax6-IR cells was lower in the hypoxic group than in the control group in the cerebral cortex. In contrast, in the SVZ and SGZ, the density of Pax6-IR cells was greater in the hypoxic group than in the control group. ${ }^{*} p<0.005$.

prenatal hypoxia, due to the various effects of Pax6 on the diverse processes of neurogenesis, including cell survival.

\section{Acknowledgements}

This work was supported by a grant from the Clinical Medicine Research Institute of Chosun University Hospital (2012).

\section{References}

1 Doetsch F, Caille I, Lim DA, Garcia-Verdugo JM and Alvarez-Buylla A: Subventricular zone astrocytes are neural stem cells in the adult mammalian brain. Cell 97(6): 703-716, 1999.
2 Jones KS and Connor B: Proneural transcription factors dlx 2 and pax6 are altered in adult svz neural precursor cells following striatal cell loss. Mol Cell Neurosci 47(1): 53-60, 2011.

3 Doetsch F, Garcia-Verdugo JM and Alvarez-Buylla A: Cellular composition and three-dimensional organization of the subventricular germinal zone in the adult mammalian brain. $\mathbf{J}$ Neurosci 17(13): 5046-5061, 1997.

4 Kempermann G, Gast D, Kronenberg G, Yamaguchi M and Gage FH: Early determination and long-term persistence of adult-generated new neurons in the hippocampus of mice. Development 130(2): 391-399, 2003.

5 Lois C and Alvarez-Buylla A: Proliferating subventricular zone cells in the adult mammalian forebrain can differentiate into neurons and glia. Proc Natl Acad Sci USA 90(5): 2074-2077, 1993. 
6 Simpson TI and Price DJ: Pax6; a pleiotropic player in development. Bioessays 24(11): 1041-1051, 2002.

7 Sakurai $\mathrm{K}$ and Osumi N: The neurogenesis-controlling factor, pax6, inhibits proliferation and promotes maturation in murine astrocytes. J Neurosci 28(18): 4604-4612, 2008.

8 Maekawa M, Takashima N, Arai Y, Nomura T, Inokuchi K, Yuasa $\mathrm{S}$ and Osumi N: Pax6 is required for production and maintenance of progenitor cells in postnatal hippocampal neurogenesis. Genes Cells 10(10): 1001-1014, 2005.

9 Osumi N: The role of pax6 in brain patterning. Tohoku J Exp Med 193(3): 163-174, 2001.

10 Walther C and Gruss P: Pax-6, a murine paired box gene, is expressed in the developing cns. Development 113(4): 14351449, 1991.

11 Osumi N, Shinohara H, Numayama-Tsuruta K and Maekawa M: Concise review: Pax6 transcription factor contributes to both embryonic and adult neurogenesis as a multifunctional regulator. Stem Cells 26(7): 1663-1672, 2008.

12 Gotz M: Glial cells generate neurons - master control within cns regions: Developmental perspectives on neural stem cells. Neuroscientist 9(5): 379-397, 2003.

13 Hack MA, Sugimori M, Lundberg C, Nakafuku M and Gotz M: Regionalization and fate specification in neurospheres: The role of olig2 and pax6. Mol Cell Neurosci 25(4): 664-678, 2004.

14 Daval JL and Vert P: Apoptosis and neurogenesis after transient hypoxia in the developing rat brain. Semin Perinatol 28(4): 257263, 2004.

15 Kernie SG and Parent JM: Forebrain neurogenesis after focal ischemic and traumatic brain injury. Neurobiol Dis 37(2): 267274, 2010.

16 Derrick M, He J, Brady E and Tan S: The in vitro fate of rabbit fetal brain cells after acute in vivo hypoxia. J Neurosci 21(7): Rc138, 2001.

17 Levison SW, Rothstein RP, Romanko MJ, Snyder MJ, Meyers RL and Vannucci SJ: Hypoxia/ischemia depletes the rat perinatal subventricular zone of oligodendrocyte progenitors and neural stem cells. Dev Neurosci 23(3): 234-247, 2001.

18 Chung E, Kong X, Goldberg MP, Stowe AM and Raman L: Erythropoietin-mediated neuroprotection in a pediatric mouse model of chronic hypoxia. Neurosci Lett 597: 54-59, 2015.

19 Briscoe TA, Tolcos M, Dieni S, Loeliger M and Rees SM: Prenatally compromised neurons respond to brain-derived neurotrophic factor treatment in vitro. Neuroreport 17(13): 13851389, 2006.

20 Kronenberg G, Gertz K, Cheung G, Buffo A, Kettenmann H, Gotz $\mathrm{M}$ and Endres M: Modulation of fate determinants olig2 and pax6 in resident glia evokes spiking neuroblasts in a model of mild brain ischemia. Stroke 41(12): 2944-2949, 2010.

21 Hayashi TT and Dorko ME: A rat model for the study of intrauterine growth retardation. Am J Obstet Gynecol 158(5): 1203-1207, 1988.

22 Gilbert $\mathrm{M}$ and Leturque A: Fetal weight and its relationship to placental blood flow and placental weight in experimental intrauterine growth retardation in the rat. J Dev Physiol 4(4): 237-246, 1982.
23 Fagel DM, Ganat Y, Silbereis J, Ebbitt T, Stewart W, Zhang H, Ment LR and Vaccarino FM: Cortical neurogenesis enhanced by chronic perinatal hypoxia. Exp Neurol 199(1): 77-91, 2006.

24 Semenza GL, Roth PH, Fang HM and Wang GL: Transcriptional regulation of genes encoding glycolytic enzymes by hypoxiainducible factor 1. J Biol Chem 269(38): 23757-23763, 1994.

$25 \mathrm{Li}$ QF, Wang XR, Yang YW and Lin H: Hypoxia upregulates hypoxia inducible factor (hif)-3alpha expression in lung epithelial cells: Characterization and comparison with hif1alpha. Cell Res 16(6): 548-558, 2006.

26 Wang GL, Jiang BH, Rue EA and Semenza GL: Hypoxiainducible factor 1 is a basic-helix-loop-helix-pas heterodimer regulated by cellular o2 tension. Proc Natl Acad Sci USA 92(12): 5510-5514, 1995.

27 Sun FL, Wang W, Zuo W, Xue JL, Xu JD, Ai HX, Zhang L, Wang XM and Ji XM: Promoting neurogenesis via wnt/betacatenin signaling pathway accounts for the neurorestorative effects of morroniside against cerebral ischemia injury. Eur J Pharmacol 738: 214-221, 2014.

28 Kohwi M, Osumi N, Rubenstein JL and Alvarez-Buylla A: Pax6 is required for making specific subpopulations of granule and periglomerular neurons in the olfactory bulb. J Neurosci 25(30): 6997-7003, 2005.

29 Ross HH, Sandhu MS, Cheung TF, Fitzpatrick GM, Sher WJ, Tiemeier AJ, Laywell ED and Fuller DD: In vivo intermittent hypoxia elicits enhanced expansion and neuronal differentiation in cultured neural progenitors. Exp Neurol 235(1): 238-245, 2012.

30 Hevner RF, Hodge RD, Daza RA and Englund C: Transcription factors in glutamatergic neurogenesis: Conserved programs in neocortex, cerebellum, and adult hippocampus. Neurosci Res 55(3): 223-233, 2006.

31 Klempin F, Marr RA and Peterson DA: Modification of pax6 and olig2 expression in adult hippocampal neurogenesis selectively induces stem cell fate and alters both neuronal and glial populations. Stem Cells 30(3): 500-509, 2012.

32 Swanson DJ, Tong Y and Goldowitz D: Disruption of cerebellar granule cell development in the pax6 mutant, sey mouse. Brain Res Dev Brain Res 160(2): 176-193, 2005.

33 Estivill-Torrus G, Pearson H, van Heyningen V, Price DJ and Rashbass P: Pax6 is required to regulate the cell cycle and the rate of progression from symmetrical to asymmetrical division in mammalian cortical progenitors. Development 129(2): 455466, 2002.

34 Chung YY, Jeon YH and Kim SW: Cortical neuronal loss after chronic prenatal hypoxia: A comparative laboratory study. J Korean Neurosurg Soc 56(6): 488-491, 2014.

Received August 22, 2017

Revised September 14, 2017

Accepted September 19, 2017 